\title{
Health as the Moral Principle of Post-Genomic Society : \\ Data-Driven Arguments Against Privacy and Autonomy
}

\section{Snell, Karoliina}

2019-04

Snell , K 2019 , ' Health as the Moral Principle of Post-Genomic Society : Data-Driven Arguments Against Privacy and Autonomy ', CQ : Cambridge quarterly of healthcare ethics :

the International journal for healthcare ethics committees , vol. 28 , no. 2 , pp. 201-214 . https://doi.org/10.1017/S096

http://hdl.handle.net/10138/307205

https://doi.org/10.1017/S0963180119000057

acceptedVersion

Downloaded from Helda, University of Helsinki institutional repository.

This is an electronic reprint of the original article.

This reprint may differ from the original in pagination and typographic detail.

Please cite the original version. 


\title{
Health as the Moral Principle of Post-Genomic Society: Data-Driven Arguments Against Privacy and Autonomy
}

\section{KAROLIINA SNELL}

\begin{abstract}
In Finland, as well as all over the globe, great weight is put on the possibilities of large data collections and 'big data' for generating economic growth, enhancing medical research, and boosting health and wellbeing in totally new ways. This massive data gathering and usage is justified by the moral principle of improving health. The imperative of health thus legitimizes data collection, new infrastructures and innovation policy. It is also supported by the rhetoric of health promotion. New arrangements in health research and innovations in the health sector are justified, as they produce health, while the moral principle of health also obligates individual persons to pursue healthy lifestyles and become healthy citizens. I examine how, in this context of Finnish data-driven medicine, arguments related to privacy and autonomy become silenced when contrasted with the moral principle of health.
\end{abstract}

Keywords: data-driven medicine; health; privacy; biobanks; genomic knowledge; autonomy; choice; strategy; innovation policy; consent

\section{Introduction}

Contemporary post-genomic health research is built on large data infrastructures, where genomic data is combined with, for example, other omics data, electronic patient records, lifestyle and wellbeing data and register information. The scale and scope of utilizing healthrelated data is as unprecedented as the potential associated with it. Nation states as well as multinational organizations are placing great emphasis on developing methods for harnessing the potential of health data. The OECD ${ }^{1}$ has identified health services as one of the sectors where the adoption of data analytics is seen to have the highest impact in the relative short run. This especially concerns genomic information and different types of data collected through digital health applications. The European Commission has highlighted three areas in the field that require further action:

“- citizens' secure access to and sharing of health data across borders;

- better data to advance research, disease prevention and personalised health and care;

- digital tools for citizen empowerment and person-centred care."2 
These developments can be grouped under the heading of data-driven medicine. Concepts linked to data-driven medicine — such as personalized medicine and digital health-are gaining ground with scientists, health professionals and policy makers in Finland and internationally. ${ }^{3,4,5,6}$ What is common with these new rationales of health care is that they are based on creating vast amounts of information about both individuals and populations. New health services, medical research and diagnostic tools are created on big data platforms. With data-driven medicine, it is said that the focus of health care also shifts from treatment of patients to prediction and prevention of diseases. ${ }^{7,8}$ Large amounts of data are thus being collected, aggregated, connected, transformed, and utilized, to prevent people from getting ill.

Data-driven medicine is characterized as a paradigm change, and its advances have been argued for by using metaphors such as 'revolution', to depict the radical changes envisioned for health care and patients. ${ }^{9,10,11}$ The attendant developments have also been analyzed through the expectations created in discourses around personalized health and genomic medicine. ${ }^{12,13}$ In this article, I bring forth a distinctive set of arguments that the proponents of data-driven medicine use in strategies and public discussion to promote their cause, or 'revolution'.

I focus on the predominant idea that data-driven medicine enhances peoples' health, and is therefore acceptable and desirable. Intensified health data sourcing, ${ }^{14}$ attracting international business to mine health data, and creating new enabling regulations are all justified as measures for achieving better health. In the public discussion on data-driven medicine, health as the moral principle supports two lines of argument. First of all, aiming toward health and a healthy society are grounds for justifying the building of new data infrastructures such as biobanks, and endorsing economic activities and innovation in the health sector. Without data collection, innovation, and research and development, no new cures can be developed. Secondly, the moral principle of health obligates individual persons to pursue healthy lifestyles, and health in general. Healthy people are good and inexpensive citizens. The ideal citizen does not only know what good health is, but also becomes committed to its fulfilment through selfmanagement and lifestyle choices. ${ }^{15,16}$ While these types of reasoning have existed before, data-driven medicine brings new aspects to the arguments, and binds them together in new ways. For example, arguments related to privacy and autonomy become framed as secondary, when contrasted with the moral principle of health.

Because health is at question, it is very difficult to argue against data collection and use. Daniel Solove has examined the notion of privacy in the setting of national security in the USA, and how in public discussion, privacy becomes frequently balanced against security-increasing one lessens the other. ${ }^{17} \mathrm{He}$ argues that it is often believed that people have to trade privacy in order to be more secure. The same seems to apply to post-genomic, data-driven health. When opposing arguments such as those related to privacy are balanced against health, arguments for better health usually win, while those related to privacy become silenced.

I will also show that the predominant line of argumentation prioritizes health and extensive data gathering and processing over not only privacy, but also the autonomy of the individual. However, the autonomy of the individual is simultaneously highlighted in prevailing discourses that emphasize freedom of choice in health promotion and health services. Datadriven medicine is perceived to enhance freedom of choice, and bring empowerment to individuals. ${ }^{18,19,20}$ However, the rationale that places health as the moral principle also undermines the autonomy of individuals. I analyze this 'contradiction of autonomy' and how 
the premises of argumentation make it difficult to combine the two argumentation strategiesthe moral principle of health, and freedom of choice - and concomitantly create coherent and sustainable health data policy.

These contradictory arguments, and the supremacy of health, are analyzed in the context of Finnish discussions on genomics, biobanks and personalized medicine as my empirical starting point, but I also reflect the findings to European and global discussions. I contribute to the discussions on how to balance individual and communal ethical principles, ${ }^{21,22,23,24,25}$ not by taking a normative position, but by demonstrating the difficulties in argumentation around datadriven medicine, to find a balance between the two.

\section{Context and Material}

The empirical base for my analysis comes from expert discussions in Finland about biobanks and uses of genomic knowledge and other health data that have gone on since 2013. The analysis builds especially on three processes in Finland: (1) the implementation of the Biobank $\mathrm{Act}^{26}$ and its renewal, (2) the drafting and implementation of the National Genome Strategy, and (3) the process of changing the legislation and practices of secondary use of social and health data.

Biobanks are research infrastructures that collect, store and circulate human biological samples (blood, tissue, urine etc.) and other data from sample donors (lifestyle information, patient records, register data etc.) for future research purposes. The Biobank Act came to force in Finland in autumn 2013. The act is internationally unique, as it regulates directly and solely, biobanks of all types. ${ }^{27}$ Other than Finland, only few countries, such as Estonia, China and Taiwan, have specific biobank legislation. ${ }^{28}$ The Finnish Biobank Act applies to both public and private biobanks, and the whole range of biobanks from population to clinical and diseasebased biobanks. The Biobank Act defines criteria for operating a biobank, such as informed consent procedures, the return of research results, and access to data by third parties. ${ }^{29}$

After the enforcement of the Biobank Act in 2013, ten biobanks have been established and registered, as required by the Act, and they have started to implement the requirements of the law in their practices. This has not always been easy. There have been many seminars and events to ponder the problems and possibilities of the Biobank Act, as well as the future of Finnish biobanking. Currently, the biobanks are also participating in the restructuring boom. There have been some mergers as well, and a cooperative of six clinical biobanks, 'Biobank Finland' has been established.

The second process is the drafting and implementation of the Finnish National Genome Strategy, "Improving Health through the Use of Genomic Data," 30 that started in 2014 by the initiative of the Ministry of Social Services and Health and Sitra, a fund operating under the Finnish Parliament. The objective of the drafting process was to identify central measures to guarantee full-scale use of genomic data in healthcare. The strategic vision was outlined as follows: "In 2020, genomic information will be effectively used in Finland to achieve population health benefits." ${ }^{31}$ In spring 2016, the government announced that it would support the aims of the Genome Strategy, including the establishment of a national Genome Centrea national reference database and expert infrastructure that brings together all major actors in genomics in Finland. The establishment of the Genome Centre is currently in progress. 
The third process concerns the drafting of legislation concerning the secondary usage of health and social data that has been prepared ${ }^{32}$ and is now in parliamentary discussion. The aim of this process was to create permissive legislation that enables "full scale utilization" of health, social service, and wellbeing data of Finns. ${ }^{33}$ Part of the process has been also to build infrastructure that supports the utilization of the data. This involves establishment of a single service and permit operator that combines and processes the data (registers, biobanks, electronic patient records, etc.) for different uses (research and development, planning, steering and education), and processes permit applications. The combination of data is made possible by the personal identification number all Finnish residents have.

I have participated in both open and closed seminars and discussions related to biobanks, the Genome Strategy and health data use between 2013-2018. In addition, I have attended numerous other seminars, events and discussion forums related to personalized medicine, digital health technologies and genomic knowledge. I have made notes, and used the background material and presentation slides to study the lines of argumentation experts use to promote data-driven medicine. The experts-who are the participants at these events-include different stakeholders such as: representatives from ministries and funding agencies, regulatory officials, biobank managers, researchers in genomics and biomedicine, medical professionals, ICT, juridical and ethical experts, and representatives of companies. I have also followed the discussions related to the subject in the media-articles, tweets and blogs written by stakeholders, or their interviews in the media-and read document material related to biobanks, the Genome Strategy and secondary use of health data.

This article focuses on one set of arguments and what kinds of justification in support of datadriven medicine these arguments entail. It does not aim to create a full picture of the discussions in Finland or internationally. I will not make distinctions between different types of experts and their argumentation strategies or correlate their arguments to the interests and positions of different stakeholders. ${ }^{34}$ This is also due to the fact that, perhaps a bit surprisingly, the type of argumentation that I present here is used by experts regardless of their position, role or affiliation. The emphasis and tone of argumentation varies, but similar structures of argumentation crosscut the stakeholders, "We are doing this for better health". There are of course many other types of arguments related to the promotion of data-driven medicine. I have chosen to analyze the above mentioned for their predominance, and I want to highlight the importance of the ethical premises of the arguments that emphasize either the autonomy and privacy of the individual or the ultimate goal of health made possible through extensive data gathering and processing.

\section{The Moral Principle of Health}

I focus the prevalent idea that data-driven medicine improves peoples' health and is therefore acceptable and desirable. The objective of improving health frames medical research and datadriven medicine, which are seen to lead directly and unquestionably to better health. This happens by two means: creating new health innovations and supporting infrastructures, and encouraging people to actively aim for better personal health.

The starting point of argumentation crystallizes around the idea that, "with data-driven medicine, we can make people healthier." Data-driven medicine is often replaced with 
expressions such as genomic knowledge, biomedical research, biobanks or health data, but the core idea is the same-better health is reached through gathering, combining and using health data. Demonstrating examples come from the roll-up banners that Finnish biobanks put up in seminars and events which include slogans such as: "Research for the good of the health of Finns"; "Help us to build a healthier future"; "Health is the biggest gift of all"; "Action for better health"; and "Better health through research".

This kind of advertisement or line of argumentation places health and all efforts to promote health as the primary and unconditional objective. Whether medical research, biobanks and data-driven medicine always lead to better health, or even new cures and treatments, is not questioned. Nor is whether all people crave for health above other virtues in life. Research and innovations are regarded at face value to result in improvements in health, and so are new infrastructures such as biobanks, and legislative reforms. Health as a goal cannot easily be resisted. What could be more important than peoples' health?

The principle of health also legitimizes the gathering, storing and processing of data. Data is a source of knowledge for research, and new knowledge is needed to solve problems. To solve health problems, one only has to gain access to knowledge, and this happens through data. Data-driven medicine requires information from the individuals as well as from reference populations. The data is not only explicitly health information such as diagnoses, patient records, or genomic profiles. The perceived promise behind data-driven medicine is in epigenomics and the possibilities of combining all sorts of data from self-monitoring data, to school grades or GPS tracking information. ${ }^{35,36}$ The moral principle of health therefore becomes associated with the use of all kinds of data, not only health records.

Databases also offer new possibilities for companies and the medical industry to gain profit, and develop data-driven business. But leaning on health, as the moral principle, is a more acceptable line of argumentation than claiming legitimation for producing new innovations and economic competitiveness, which are also commonly used as arguments for data-driven medicine.$^{37}$ Research shows that Finns, among other European citizens, are more skeptical about health research when it has connections to business, and when it is perceived to be commercial. ${ }^{38,39}$

Publicly funded research that is supposed to enhance national health or personal health is deemed more acceptable. So, even though strategies and discussions are aiming to enhance Finnish competitiveness in the global genomics market ${ }^{40}$, it is more convenient to refer to the underlying principle of health. The suspiciousness of Finns toward big pharma, for example, is often countered with an argument from the expert side: "Don't they understand that we need companies to develop medicine for their illnesses?" Companies and business are needed, to obtain the ultimate goal of better health. Whenever the commercialization arguments or rhetoric promoting national innovativeness and competitiveness are questioned, health as the ultimate goal of companies as well is brought to the fore. International investments in genomic research and development, for example, "are of direct benefit to Finns and the Finnish healthcare system." ${ }^{41}$ So even if Finnish documents and strategies do not always explicitly name health as the primary and ultimate goal, as it is often overshadowed by economic goals, health is the moral principle that is referred to.

The other dimension of the moral principle of health is related to the duty of individuals or citizens to promote their own health. A model of healthy citizens and health promotion has 
been adopted by all industrialized countries - both in so-called liberal and welfare stateswhere people are considered to be autonomous, active and responsible partners in managing their own health. ${ }^{42,43,44}$ Robert Crawford has written about healthism to describe the increasing focus on health and the responsibility of the individual for her own health. ${ }^{45}$ Healthism places the problem of health and illness at the level of the individual. While healthism is not a new tendency, ${ }^{46}$ data-driven medicine offers new possibilities to bring health promotion and personal responsibility into a novel relationship with more precise and individualized measures.

Data analytics creates masses of new information for the individual to respond to. This highlights the moral dimension of personal risk-with more and more personalized information available, one should take control of one's life. The data-driven medicine paradigm thus continues from the idea that people can and should take personal responsibility for their health, and furthermore deploys a large amount of data to produce more accurate and personalized possibilities for improving one's health. The P4 ideology - predictive, preventive, personalized and participatory medicine - has gained ground in Finland, and the investments to biobanks, the Genome Centre, and legislative reforms are said to serve the development of personalized medicine and the empowerment of individuals. Health databases and personalized analytics will "provide the basis for concrete action by consumers to improve their health as they observe the impact of life-style decisions." 47

\section{The complexity of Privacy}

The uses of personal data and possibilities to individually target health promotion have raised alarm in relation to the privacy of individuals. Can privacy of individuals be guaranteed in the databases? Is genome data ever anonymous? But when health is used as the moral principle, defending privacy arguments becomes difficult. Solove has written about privacy in the context of national security in the USA, and how in public discussion, privacy becomes commonly balanced against security in settings in which increasing one lessens the other. He claims that it is often assumed that people have to make a trade-off. In order to be more secure one has to be willing to sacrifice privacy. Privacy is then viewed as a right of an individual which is balanced against the common good. ${ }^{48}$

The same seems to apply to health in the data-driven era. In order to enhance national public health, or development of medicine, one has to be ready to sacrifice personal privacy. If people are too worried about their privacy and do not participate in biobanks, or share their health and genomic data for research, they are obstructing the common good and health of others. Referring to privacy rights becomes associated with negative notions such as selfishness and free riding. ${ }^{49,50}$ If people do not participate in research, or are not willing to give their data for innovation purposes for privacy reasons, they will be using services based on other peoples' data for free. For the good of others, solidarity and even national competitiveness, privacy becomes a less-valid argument than health.

In Finland, the building of data infrastructures and innovation ecosystems are also framed as national projects ${ }^{51}$, which makes opposing them with requests for personal privacy seem futile and selfish. Because privacy is seen as an individual right and the health of all people as a societal interest, balancing between them is difficult. Solove therefore suggests that privacy 
should not be seen only as a right of the individual, but as a social value and something that is not in opposition to common good.52 Other authors have pointed to the dichotomies and polarities present in ethical discussion, such as individual vs. community or autonomy vs. discipline. ${ }^{53,54}$ These dichotomies are visible in the discussions around data-driven medicine, even though it might not be constructive to situate them in those extremities in principle or in practice. As Solove states: "Sacrificing privacy does not automatically make us more secure. Not all security measures are invasive of privacy." 55

While privacy is often listed as one value that needs to be secured in data-driven medicine, there are many other ways of rejecting concerns over privacy in expert arguments or public discussion. A common way of dismissing peoples' concerns over privacy is to refer to the idea that people already voluntarily share all kinds of information. I have heard numerous arguments where the starting point is that people do not care about privacy, as "they are already sharing everything" on social media or are sending their saliva samples to be tested in direct-toconsumer genetic testing companies in the USA. The logic is that biobanking or data-driven medicine should not therefore be considered as harming people's privacy in an unprecedented way. Also Donna Dickenson, in her work on biotechnology and genetics, points to the tendency to fall back on the argument: "What is the problem, if that's what people choose to do?."56 Genomics, data-driven medicine or biobanks bring nothing new to privacy, goes the argument. People are willing to voluntarily share their information to many more dubious causes (that don't follow health as a moral principle), so why should data-driven medicine be different? And the argument continues, biobanks and genomic research already need to follow very strict regulation and data protection principles. The data is much more secure in the hands of Finnish biobanks and the Finnish health care system (that has peoples' health as the ultimate goal) than with consumer genetics companies or large companies such as Google.

The "They are already sharing everything" reasoning is closely connected to what Solove terms as the "I've got nothing to hide" argument. In his analysis on discussions of national security in the USA, he brings forth a number of examples of how the argument is used to support the use of personal data. This type of argumentation is also present in the everyday discussions of people, as cited by Solove: "Do I care if FBI monitors my phone calls? I have nothing to hide." 57 Similar argumentations can be found in the health data field. People can consider themselves to be ordinary and to be living a life that can withstand scrutiny, and they therefore do not have anything to hide. Data in biobanks and genomic information could be potentially harmful, but not to an average person with nothing to conceal. ${ }^{58}$ It is therefore not only the experts that foster this line of argumentation.

The problem with the "nothing to hide" argument, according to Solove, is that it assumes that privacy is only about hiding bad things. The tendency here is that other problems related to privacy-such as discrimination, exclusion or secondary uses of data-do not get acknowledged. These problems bear different moral components besides or in addition to health, such as equality. Solove continues that using the "nothing to hide" argument denies the existence of a privacy problem. ${ }^{59}$ This applies to the "they already share everything" argument as well. It rejects the presence of problems related to gathering, storing and disseminating private information by focusing on the perceived lack of concern of people toward their personal information. Thus, privacy is used narrowly, and becomes easily dismissed by referring to the perceived conduct and opinions of people who already do not care about privacy. 
These arguments also resemble the so called 'post-privacy thinking', that claims privacy to be outdated. ${ }^{60,61}$ It is seen as more valuable to share data than keep it private. A prime example of this thinking comes from the portal PatientsLikeMe, which is a kind of Facebook for patients, where you can create a profile based on your disease, symptoms and medications. ${ }^{62}$ PatientsLikeMe has promoted an openness policy. The idea is that the more you share, the more you can benefit. So the argumentation goes that sharing data can bring benefits to one's health'. Interestingly, similar thinking is present in the reforms of the Finnish public health care system. By sharing your data, you participate in the common good, and the improvement of personal and public health. Sharing therefore has a moralistic undertone that implies that it is good to share ${ }^{63,64}$, and if you don't want to share, you have dubious motives or something to hide. Sharing your data can also be a condition for receiving personalized health servicesif you don't share your data, the health care system has inadequate information to treat you of offer you best possible services.

Another common way of interpreting privacy in a narrow manner is to see privacy as a technical problem of information security. In many discussions, privacy becomes reduced to a problem that can be solved by legislation and secure ICT systems, and not a moral concern. Data security and regulations are assumed to offer privacy protection for the Finnish people. All social and ethical questions seem to be handled when data security is being taken care off. When privacy is reduced to only technical and legal protection (or considered as being only about hiding bad stuff) other questions of privacy become undermined. And there are indeed, many other types of harm beyond the exposing one's personal health data, such as issues related to exclusion from services, misinterpretation of data, and decisional interference.

If privacy is more than just about hiding bad stuff or keeping information secure, what is it then? Solove claims that privacy "is too complicated a concept to be boiled down to a single essence". ${ }^{65}$ Therefore he sees that it is more fruitful to talk about privacy through particular problems, and not as an all-encompassing concept. Helen Nissenbaum has also written about information gathering and privacy, and developed the concept of contextual integrity. ${ }^{66}$ Contextual integrity ties protection of privacy to norms of each specific context and builds on the idea that information gathering and dissemination should obey the governing norms of the context.

The contextualization of data becomes a highly relevant issue in the government-led process, to enable, reorganize, and streamline the secondary use of social and health data in Finland. ${ }^{67}$ The process aims to bring together all Finnish health and social data (including biobank and genome data) under one service operator. It is argued that by concentrating data with one service operator, data security increases, and this enhances the privacy of the individuals. But if we look at the privacy from the more nuanced viewpoints of Nissenbaum and Solove, secondary use removes data from its original context and thus creates possibilities for breaches of privacy.

\section{Autonomy and the Imperative of Health}

In addition to privacy, the idea of autonomy is being balanced against the principle of health. Concomitantly, the moral principle of health is used to dilute arguments for autonomy. This becomes apparent in the popular statements that argue: "What right do people have not to 
participate, when research can save lives?". This line of argumentation is based on an idea that data-driven medicine based on solidarity or a duty to share data, with health as the ultimate objective, is more valuable than peoples' autonomous decisions to participate, or not, in medical research. The discourses sustain the dichotomy between individual autonomy and common good. This line of argumentation also presupposes that research will result in improvements in health or at least, has that as an aim. Participation, as such, is therefore seen as a sign of contributing to health, and nobody should thus be allowed to resist it.

Data-driven medicine requires as much data as possible, and from as many people as possible. Biobanks need participants, and sometimes their informed consent, to use their samples and medical data. The Finnish Biobank Act requires all biobanks to ask for an informed consent from new sample donors. The consent is defined as broad, basically allowing uses for all medical research and development. Finnish hospital biobanks are based on an idea that in the future, samples are not only given once to a biobank but are taken routinely during every procedure-blood test or operation - in the hospital. Data is also gathered cumulatively from people and from multiple sources and registers. Sustainability of biobanks, and the continuous accumulation of data, therefore requires input from the public. ${ }^{68}$

Recruiting and committing people to biobanking, for example, has not been easy. Experts have become worried, because participation rates are declining in epidemiological research ${ }^{69}$ and Finnish biobanks have not been able to recruit as many participants as desired. ${ }^{70}$ Securing large-enough participation rates has become one of the major topics in Finnish biobank discussions in the last two years. As a result, a new strand of argumentation emerged that promoted the changing of the consent model of biobanks from broad informed consent to presumed consent with an opt-out clause. ${ }^{71,72}$ This would mean that all Finns would be biobank participants by default, unless they specifically opted-out of the system. In addition, the latest plan for renewing the Biobank act contains a proposal that would enable sample gathering for biobanks in connection to routine hospital operations, without the consent of the patient. These suggestions reveal considerable departures from the previous discussions, where autonomy of individuals to make a decision about participating to a biobank was deemed crucial, and one of the best characteristics of the Finnish Biobank Act. One of the main purposes of the Biobank Act was to secure the privacy and autonomy of the individuals and "to support research that utilizes human samples, to promote the openness of the use of samples and to secure the protection of privacy and autonomy in handling the samples." 73

During the first years after the implementation of the Biobank Act, the Act and its definitions of broad consent were widely hailed as successful. Finland was seen as having "the best Biobank Act in the world." The wide consent model and possibilities for contacting participants again were viewed as supportive of the health goal, and the broad consent was regarded as a prerequisite for biobanking. But the legal bases and functioning of wide consent have now been problematized. The interpretation of the GDPR in Finland supports a view that broad consent cannot be used as grounds for gathering samples and data. The solution presented in Finland is to refer to the legal bases of data collection-if data procedures are statutory and defined in legislation, informed consent is not necessary. The opt-out model would transform the collection of biobank samples and data to resemble register information. Many kinds of register data are collected from individuals in Finland routinely, without consent and by referring to the legislation. It is possible to combine these register and other data sources, using the personal identification number each Finn has. 
As argumentation is shifting from consent to opt-out, the autonomy of individuals is being subordinated to the need for gathering data. This similarity to register information is supported by arguing: "Lots of data has been gathered this way already for years." The argumentation resembles the above-explored argumentation of "They are already sharing everything." In this line of thinking, biobanking and data-driven medicine are not seen to indicate a considerable change in data collection and sharing practices. Extra protective measures may therefore seem unnecessary, and genomic information and biobank data could be gathered and combined with other health and social data without explicit consent from Finns. Another argument has been presented to promote the opt-out model for biobanks in the name of autonomy. It is claimed that because informed consent can never be totally informed in the case of biobanks, the autonomy of individuals becomes respected more through the opt-out model. People are not asked to commit to something that is unclear, but if they regard biobanking unclear or problematic they can opt-out. Therefore opt-out is regarded as guaranteeing better possibilities for individuals to take a stance.

The active, empowered and choice-making citizen has been identified as a major actor in the neo-liberal society, new public health movement, and personalized medicine. ${ }^{74,75}$ The international strategies for personalized medicine are rooting for empowerment, ${ }^{76}$ and the public discussions around possibilities of data-driven medicine also emphasize autonomy and choice. Indeed, autonomy, choice and empowerment are also used as arguments to support data-driven medicine in the Finnish discussions. For example, the structural health care reform ongoing in Finland is also tied closely to enhancing the freedom of choice of individuals to choose their health care and service providers. Personalized medicine is also seen to increase the likelihood of people to make better health and life style choices. The new personalized health promotion logic is closely connected to the value of choice. Choice and autonomy are used in the same discussions, and by same people who use the health as moral principle argumentation to suppress individual choices and autonomy.

Dickenson has claimed that autonomy, and its partner, choice, are paramount values and mantras in personalized medicine, known here as data-driven medicine. She criticizes the loose use of the concepts. Taking personal choice at face value closes down deeper analysis of facts. She continues by saying that referring to choice is a lazy argument. ${ }^{77}$ Annemarie Mol critiques not the general concept of choice but the generalization of choice, and how it can be contrasted with "no choice". She points to the practices and logics that are behind referring to patient choice, and how these logics and practices can change the ideal of, and even clash with good care. ${ }^{78}$ Similarly, Luca Chiapperino and Giuseppe Testa write that the related concept of empowerment is crucial to current proposals of healthcare reform across Europe and worldwide. They are also critical of using this notion in argumentation as, according to them, it is unclear whether empowerment is used for its intrinsic (moral) or instrumental (legitimation) value, or if it is used solely to support economic motivations. ${ }^{79}$ It is therefore not clear whether the emphasis on choice actually enhances autonomy or if it is only used as a rhetorical tool for promoting practices that require compliance.

Choice and empowerment are made to serve the objective of health from an apparently individualistic approach that does not concur with the more communitarian ideas of participation in biomedicine, including the ideas of solidarity and anti-free-riding, in which everyone is expected to share their data. In many ways, these discussions form a contradiction 
of autonomy, where the idea of autonomy is simultaneously promoted through choice, and silenced by focussing on common need to enhance data-driven medicine.

\section{Conclusions}

As I have demonstrated, argumentation that relies on the moral principle of health tends to undermine the arguments related to autonomy and privacy. While these latter concepts have been associated with individual rights and empowerment in the context of data-driven and personalized medicine, they seem to be difficult to combine with the more communal approaches that are supported by the moral principle of health, such as common good, public health or national competitiveness. Finding a balance between individual and communal ethical principles and dichotomies such as autonomy vs. discipline or private vs. public has been called for by several authors. ${ }^{80}$ It has been pointed out that data is gathered from individuals but also applied to large populations, which makes it necessary to think about ethics as related to both individuals and collectives. ${ }^{81}$ My analysis of public discussions around datadriven medicine in Finland demonstrates that arguments used to support its development are contradictory and fail to find a balance between the polarized arguments.

The moral principle of health supports both the building of data infrastructures and ecosystems and the enhancement of personalized health promotion. With more personalized information accessible, one has better possibilities to take charge of one's health. The data-driven medicine paradigm thus continues from the idea that people can and should take personal responsibility for their health, and provides a large amount of data to produce more accurate and personalized possibilities for improving one's health. While in some instances, this puts emphasis on the autonomy of individuals, in others, the imperative of health silences these arguments. Data collection for a national project that exists for better health does not allow for choice-making free-riders, but at the same time, personalized medicine empowers people to make healthy choices. There is a seeming contradiction of autonomy at the discursive level. While other arguments adhere to the neo-liberal model of individualized healthy citizens, a communal approach emphasizing common good and populations over individuals is simultaneously articulated, but without making these arguments compatible.

A similar balancing act is present when it comes to the notion of privacy. While privacy is seen as a highly relevant issue in relation to data-driven medicine, it is at the same time being silenced and not considered to be a relevant moral argument. This happens first of all by referring to the moral principle of health that makes health a superior goal in relation to others. In this argumentation, privacy is regarded as a private good and contrasted to the common good. In addition, privacy is often interpreted as a technical problem instead of a moral one. Taking care of information security safeguards personal privacy. But as many authors have demonstrated, privacy is a more multifaceted and social phenomenon that cannot be reduced to technical security. Nor can it be dismissed be referring to arguments such as "nothing to hide", "people are already sharing their data" or "data has been gathered for decades already."

Some authors claim that there has been too much emphasis on individuals' rights, while others claim that data-driven medicine suppresses them. In this article, I'm not taking a normative stance for, or against privacy, choice or autonomy, as such, but aim to demonstrate how the loose use of the concepts in parallel with the moral principle of health makes argumentation 
and thus responsible policy development extremely difficult. Concepts like solidarity have been presented as solutions to overcome the gap. ${ }^{82}$ But applying solidarity into practice can be difficult and it requires sensitivity toward different contexts. The solidarity approach has also been criticized for overlooking the actual conditions and possibilities of people to participate in decision-making and collaborative processes. ${ }^{83}$ Solidarity can easily become a similar normative imperative to health.

\section{Notes}

1. The Organization for Economic Cooperation and Development. Data-driven Innovation for Growth and Wellbeing. Interim synthesis report. Paris: OECD Publications; 2014.

2. European Commission. Communication on enabling the digital transformation of health and care in the Digital Single Market; empowering citizens and building a healthier society. $\operatorname{COM(2018)233.~} 2018$ at 3.

3. Juengst ET Settersten RA Fishman JR McGowan ML. After the revolution? Ethical and social challenges in 'personalized genomic medicine'. Personalized Medicine 2012;9(4):429-39.

4. Tutton R. Genomics and the Reimagining of Personalized Medicine. Farnham: Ashgate; 2014.

5. Topol E. The Patient Will See You Now: The Future of Medicine Is in Your Hands. New York: Basic Books; 2015.

6. Ministry of Social Affairs and Health. Improving Health through the Use of Genomic Data. Finland's Genome Strategy. Working Group Proposal; 2015.

7. Hood L. Auffray C. Participatory medicine: a driving force for revolutionizing healthcare. Genome Medicine 2013;5:110.

8. See note 5, Topol 2015.

9. Topol E. The Creative Destruction of Medicine: How the Digital Revolution Will Create Better Health Care. New York: Basic Books; 2012.

10. See note 3, Juengst et al. 2012.

11. See note 7, Hood and Auffray 2013.

12. See note 4, Tutton 2014.

13. Hedgecoe A. Terminology and the Construction of Scientific Disciplines: The Case of Pharmacogenomics. Science, Technology, \& Human Values 2003;28(4):513-37.

14. Hoeyer K. Denmark at a crossroad? Intensified data sourcing in a research radical country. In Mittelstadt B. Floridi L., eds. The Ethics of Biomedical Big Data. Springer; 2016:73-93.

15. Lupton D. The Imperative of Health. Public Health and the Regulated Body. London: SAGE; 1995.

16. Fitzpatrick K. Tinning R. Health education's fascist tendencies: a cautionary exposition. Critical Public Health 2014;24(2)132-42.

17. Solove DJ. Nothing to Hide. The False Tradeoff between Privacy and Security. New Haven: Yale University Press; 2011.

18. Dickenson D. Me Medicine vs We Medicine. Reclaiming biotechnology for the common good. New York:

Columbia University Press; 2013.

19. König PD. The Place of conditionality and individual responsibility in a "data-driven economy". Big Data \& Society 2017; July-Dec:1-14.

20. Sharon T. Healthy citizenship beyond autonomy and discipline: Tactical engagements with genetic testing. BioSocieties 2015;10(3):295-316.

21. See note 18, Dickenson 2013 and note 14, Hoeyer 2016.

22. Prainsack B, Buyx A. Solidarity in Biomedicine and Beyond. Cambridge: Cambridge University Press; 2017.

23. Widdows H. Between the individual and the community: the impact of genetics on ethical models. New Genetics and Society 2009;28(2):173-88.

24. Sharon T. Self-tracking for health and the quantified self: Re-articulating autonomy, solidarity, and authenticity in an age of personalized healthcare. Philosophy \& Technology 2017;30:93-121. 
25. Woods S. Big Data Governance: Solidarity and the Patient Voice. In Mittelstadt B. Floridi L., ed. The Ethics of Biomedical Big Data. Springer, 2016:221-38.

26. Biobank Act (688/2012)

27. Soini S. Finland on a Road towards a Modern Legal Biobanking Infrastructure. European Journal of Health Law 2013;20(3):289-94.

28. Rothstein MA Knoppers BA. Harrell HL. Comparative Approaches to Biobanks and Privacy. Journal of Law, Medicine and Ethics 2016;44(1):161-72.

29. Tupasela A. Snell K. Cañada J. Patients, business and the state - translating health information into sustainable benefits. Policy brief for engagement practices in Canada, Finland, Iceland, Spain, UK and the US. Tekes Review 322. Helsinki: Tekes; 2015.

30. See note 6, Ministry of Social Affairs and Health 2015.

31. See note 6, Ministry of Social Affairs and Health 2015 at 15.

32. Ministry of Social Affairs and Health. Tieto hyvinvoinnin ja uudistuvien palvelujen tukena. Sote-tieto hyötykäyttöön -strategia. 2014

33. Tarkkala H. Hélen I. Snell K. From Health to Wealth: The Future of Personalized Medicine in the Making. Futures 2018:109:142-152.

34. Bourret P. Keating P. Cambrosio A. Regulating diagnosis in post-genomic medicine: Re-aligning clinical judgment? Social Science \& Medicine 2011;73(6):816-24.

35. Chiapperino L, Testa G. The epigenomic self in personalized medicine: between responsibility and empowerment. Sociological Review Monograph Series: Biosocial Matters: Rethinking Sociology-Biology Relations in the Twenty-First Century 2016;64(1):201-20.

36. Lupton D. Digital Health: Critical and Cross-Disciplinary Perspectives. Oxon: Routledge; 2018

37. See note 33, Tarkkala et al. 2018.

38. Gaskell G. Gottweis H. Starkbaum J. Broerse J. Helén I. Hobbes A. et al. Publics and biobanks: PanEuropean diversity and the challenge of responsible innovation. European Journal of Human Genetics 2013;21(1):14-20.

39. Snell K. Starkbaum J. Lauß G. Vermeer A. Helén I. From Protection of Privacy to Control of Data Streams: A Focus Group Study on Biobanks in the Information Society. Public Health Genomics 2012;15(5):293-302.

40. Ministry of Economic Affairs and Employment. Innovating together. Growth Strategy for Health Sector Research and Innovation Activities: The Roadmap for 2016-2018. 2016.

41. See note 6, Ministry of Social Affairs and Health 2015 at 31.

42. See note 20, Sharon 2015.

43. See note 19, König 2017.

44. See note 36, Lupton 2018.

45. Crawford R. Healthism and the medicalization of everyday life. International Journal of Health Services 1980;19:365-88.

46. See note 15, Lupton 1995.

47. Flores M, Glusman G, Brogaard K, Price ND, Hood L. P4 medicine: How systems medicine will transform the healthcare sector and society. Personalized Medicine 2013; 10(6):565-76, at 565.

48. See note 17, Solove 2011.

49. Forsberg JS. Hansson MG. Eriksson S. Changing perspectives in biobank research: from individual rights to concerns about public health regarding the return of results. European Journal of Human Genetics 2009; $17: 1544-49$.

50. Tinetti ME, Basch E. Patients' Responsibility to Participate in Decision Making and Research. JAMA 2013;309(22):2331-32.

51. See note 33, Tarkkala et al. 2018.

52. See note 17, Solove 2011.

53. See note 20, Sharon 2015.

54. See note 23, Widdows 2009.

55. See note 17, Solove 2011 at 34.

56. See note 18, Dickenson 2013 at 27. 
57. 50. See note 17 , Solove 2011 at 22.

58. See note 39, Snell at al. 2012.

59. See note 17, Solove 2011.

60. Burkart PA. Andersson Schwarz J. Post-privacy and ideology: a question of doxa and praxis. In Christensen M. Jansson A., ed. Media, surveillance and identity: A social perspective. New York: Peter Lang. 2014:21837.

61. Maj A., ed. Post-Privacy Culture: Gaining Social Power in Cyber-Democracy. Inter-Disciplinary Press;2014.

62. For an analysis of PatientsLikeMe see Prainsack B. Personalized Medicine: Empowered Patients in the 21 st Century? New York: New York University Press;2017.

63. Evans BJ. Power to the People: Data Citizens in the Age of Precision Medicine. Vanderbilt Journal of Entertainment \& Technology Law 2017;19(2)243-65.

64. See note 22, Prainsack and Buyx 2017.

65. Solove DJ. Understanding Privacy. Cambridge: Harvard University Press;2008 at 113.

66. Nissenbaum H. Privacy as contextual integrity. Washington Law Review 2004;79(1):119-58.

67. For analysis of other reforms related to electronic health records see Garrety K. McLoughlin I. Wilson R. Zelle G. Martin M. National electronic health records and the digital disruption of moral orders. Social Science and Medicine 2014;101:70-77. and Vezyridis P. Timmons S. Understanding the care.data conundrum: New information flows for economic growth. Big Data \& Society 2017;1-12.

68. See note 29, Tupasela et al. 2015.

69. Glass DC. Kelsall HL. Slegers C. Forbes AB. Loff B. Zion D. Fritschi L. A telephone survey of factors affecting willingness to participate in health research surveys. BMC Public Health 2015;15:1017.

70. Ministry of Social Affairs and Health. Report of the expert group appointed to evaluate the integration of Finnish biobanks. A report to the Ministry of Social Affairs and Health. 2016

71. Palotie A. Onko monimutkainen suostumusjärjestelmä uhka koko suomalaisen bbiopankki-toiminnan toteutumiselle? 2016; available at https://www.auria.fi/biopankki/blogit/index.php, (last accessed 6 Nov 2018).

72. Launis V. Biopankkitutkimus on läpikotaisin eettistä! 2016; available at https://www.auria.fi/ biopankki/blogit/index.php, (last accessed 6 Nov 2018).

73. See note 26, Biobank Act.

74. See note 15, Lupton 1995 .

75. See note 23, Widdows 2009.

76. See note 2, European Commission 2018.

77. See note 18, Dickenson 2013.

78. Mol A. The logic of care. Health and the problem of patient choice. Oxon: Routledge; 2008.

79. See note 35, Chiapperino and Testa

80. See note 18, Dickenson 2013 and note 20, Sharon 2015.

81. See note 14 Hoeyer 2016 and note 23, Widdows 2009

82. See note 22, Prainsack B, Buyx A 2017.

83. See note 25, Woods 2016. 